\title{
Genetic variability of the marine mussel Mytilus galloprovincialis assessed using two-dimensional electrophoresis
}

\author{
E Mosquera, JL López and G Alvarez \\ Departamento de Biología Fundamental, Facultad de Biología, Universidad de Santiago de Compostela, 15782 Santiago de Compostela, \\ Spain
}

\begin{abstract}
Two-dimensional electrophoresis (2-DE) has been used to measure the degree of genetic variability of the marine mussel Mytilus galloprovincialis. Genetic polymorphisms were detected in 33 of a total of 86 polypeptides scored among the most abundant proteins from foot samples in 38 individuals. Estimates of average heterozygosity were $0.101 \pm 0.018$ and $0.114 \pm 0.021$ in a natural and a cultured population, respectively, from the NW of the Iberian Peninsula. These are the highest estimates of average heterozygosity reported by 2-DE in an animal species to date. We consider that these data throw open the question of
\end{abstract}

the level of genetic variability detectable by two-dimensional electrophoresis. Multilocus genotype data were used to infer haplotypic frequencies by means of the EM algorithm in order to detect linkage disequilibrium between loci coding abundant proteins. Significant associations were found in $22.7 \%$ of the 406 two-locus pairs analysed. Also, clusters of loci in which all pairwise combinations exhibit statistically significant associations were detected and physical linkage between some of these loci is postulated from the linkage disequilibrium data.

Heredity (2003) 90, 432-442. doi:10.1038/sj.hdy.6800266

Keywords: genetic variability; Hardy-Weinberg departures; linkage disequilibrium; Mytilus galloprovincialis; protein polymorphisms; two-dimensional electrophoresis

\section{Introduction}

Two-dimensional electrophoresis (2-DE) is a powerful technique for separating complex mixtures of denatured proteins according to two independent criteria: charge and molecular weight (O'Farrell, 1975). Combined with nonspecific protein staining, the technique permits the visualization on a single gel of a very large number of gene products that represent the more abundant proteins in a cell or tissue. Unlike one-dimensional electrophoresis (1-DE), which is restricted to the analysis of native soluble proteins, mainly enzymes, 2-DE allows the examination of a broad spectrum of proteins and, consequently, a substantially increased number of protein-encoding loci. This suggests that 2-DE could have a great potential for the study of genetic variability of populations, in that it allows a more representative sample of the genome to be analysed. However, studies of genetic variability in natural populations of animal species by means of 2-DE have been relatively scarce, because 2-DE is technically more difficult and time consuming than 1-DE and, furthermore, because the first results revealed substantially less genetic variation than had been estimated by 1-DE (Edwards and Hopkinson, 1980; Aquadro and Avise, 1981; Neel, 1990). Moreover,

Correspondence: G Alvarez, Departamento de Biología Fundamental, Facultad de Biología, Universidad de Santiago de Compostela, 15782 Santiago de Compostela, Spain.E-mail: bfjurado@usc.es

Received 28 March 2002; accepted 10 January 2003 most studies have been focused on a few species (particularly man and Drosophila) so that the available information is to a large extent redundant and biased as a means of getting an appropriate view of the levels of genetic variability detected by $2-\mathrm{DE}$. In man, 2-DE estimates of average heterozygosity $(H)$ range from 0.000 to 0.040 for different tissues when more than 30 loci are scored (Walton et al, 1979; Smith et al, 1980; Hamaguchi et al, 1981; Comings, 1982; Goldman and Merril, 1983; Rosenblum et al, 1983; Hanash et al, 1986a,b; Takahashi et al, 1986). Other studies in man yield higher values of heterozygosity $(0.045-0.080)$ but they are based on less than 30 loci (Rosenblum et al, 1984; Asakawa et al, 1985). Apart from man, only two other species of mammals have been studied by $2-\mathrm{DE}$ with respect to genetic variability: cheetah $\left(H=0.013, \mathrm{O}^{\prime}\right.$ Brien et al, 1983) and mouse $(H=0.020$, Racine and Langley, 1980). In invertebrates, 2-DE estimates of genetic variability are restricted to two Drosophila species, in which estimated heterozygosities are rather similar to those reported for mammals ( 0.040 and 0.018 for whole body and male reproductive tract, respectively, in $D$. melanogaster and 0.000 and 0.028 for whole body and male reproductive tract, respectively, in D. simulans) (Leigh Brown and Langley, 1979; Ohnishi et al, 1982; Coulthart and Singh, 1988). Therefore, additional estimates of genetic variability by 2-DE for different species of vertebrates and invertebrates are needed. In this article, we have applied 2-DE to determine the level of genetic variation for the most abundant proteins of the marine mussel Mytilus 
galloprovincialis, remembering that molluscs are one of the taxonomic groups within the animal kingdom where the highest levels of genetic variability have been reported (the mean value of allozyme heterozygosity is $0.145 \pm 0.010$ for 105 molluscan species reviewed by Ward et al, 1992). In fact, M. galloprovincialis is a mollusc species where a particularly high value of heterozygosity for enzyme loci has been found $(H=0.240$, Grant and Cherry, 1985).

The degree of nonrandom associations, or linkage disequilibrium, between loci coding abundant proteins in natural populations is unknown. Since a large number of gene products are revealed in a single 2-DE gel, the multilocus genotype array of each individual can be directly inferred. From these 2-DE multilocus genotype data, maximum likelihood estimates of haplotype frequencies can be obtained and, therefore, associations between genetic polymorphisms can be detected in a random mating population (Excoffier and Slatkin, 1995; Slatkin and Excoffier, 1996; Weir, 1996). Furthermore, the extent of linkage disequilibrium between gene markers produced as a result of various evolutionary forces such as mutation, drift, selection or admixture during the evolutionary history of a population, can be used indirectly to infer how strongly these markers are linked on the same chromosome. If the linkage disequilibrium of the markers was created a long time ago, a strong linkage disequilibrium detected now may suggest close physical linkage between the markers, because linkage disequilibria decay with time. This principle is the basis of linkage disequilibrium mapping, an approach with a great potential to obtain information on physical linkage, which is extensively used with molecular markers (Jorde, 1995; Kaplan et al, 1995; Weir, 1996; Wu and Zeng, 2001). In this article, the first attempt to detect linkage disequilibrium between loci coding abundant proteins as detected by 2-DE is attempted in the marine mussel M. galloprovincialis.

\section{Materials and methods}

Mussel sampling and two-dimensional gel electrophoresis Adult mussels were sampled from two M. galloprovincialis populations in the NW of the Iberian Peninsula in November 1998: a midintertidal population from a waveexposed rocky shore in Ribadeo and a raft-cultured population from an inner cultivation area in the Ría de Arosa (Vilagarcía, Figure 1). Mussels were brought alive to the laboratory, where they were dissected. The foot was removed from each individual and frozen, lyophilized and stored at $-80^{\circ} \mathrm{C}$. Proteins were extracted by suspending $30 \mathrm{mg}$ of lyophilized tissue in $1 \mathrm{ml}$ of O'Farrell lysis buffer (9.5 M urea, 2\% NP-40 (v/w), 2\% ampholytes pH 7-9 and $100 \mathrm{mM}$ dithiothreitol (DTT)). The mixture was shaken for $4 \mathrm{~h}$ at $30^{\circ} \mathrm{C}$ and centrifuged at $12000 \times g$ for $30 \mathrm{~min}$.

2-DE of mussel foot was performed as described by López et al (2001). Protein loads of 127 and $255 \mu \mathrm{g}$ (in order to study the less abundant proteins) were applied to each gel. In this way, at least two gels were run for each of the individuals analysed. Isoelectric focusing using carrier ampholytes was carried out at $200 \mathrm{~V}$ for $2 \mathrm{~h}, 500 \mathrm{~V}$ for $2 \mathrm{~h}$ and $800 \mathrm{~V}$ for $16 \mathrm{~h}$. Second dimension electrophoresis was carried out at $25 \mathrm{~mA}$ per gel for $1.5 \mathrm{~h}$ followed by $35 \mathrm{~mA}$ per gel for $5 \mathrm{~h}$. 2-DE gels were stained by the silver technique of Morrisey (1981).

\section{Data analysis}

Genotype frequencies were determined by direct count on the gels. Goodness-of-fit of genotype frequencies to Hardy-Weinberg proportions at each locus was tested by means of the $\chi^{2}$ and the exact test. The exact test is very useful when the sample size and/or some genotype frequencies are small because it does not rest on asymptotic approximations for large samples (Louis

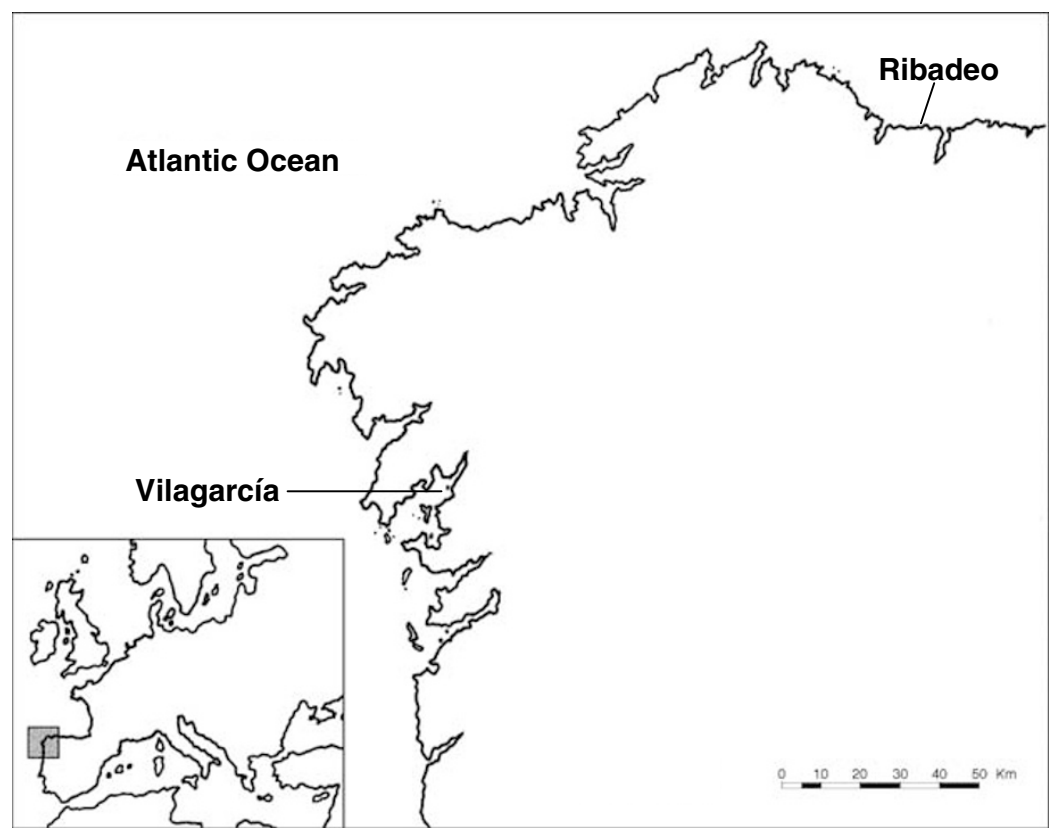

Figure 1 Map of the NW coast of the Iberian Peninsula showing the sampling sites of M. galloprovincialis. 
and Dempster, 1987; Guo and Thompson, 1992). Departures from Hardy-Weinberg proportions were measured by two $F_{\text {IS }}$ statistics: the $f_{C}$ of Weir and Cockerham (1984) and the $f_{\mathrm{T}}$ of Robertson and Hill (1984). The ratio of the estimate squared of $f_{T}$ to its variance was used as a test for $F_{\mathrm{IS}}=0$ with one degree of freedom, which is optimal for detecting Hardy-Weinberg deviations in terms of statistical power (Robertson and Hill, 1984; Rousset and Raymond, 1995). Unbiased estimates of expected heterozygosity for single loci $(h)$ and the population average heterozygosity $(H)$, calculated as the average of $h$ over all loci, were computed according to Nei (1978). The degree of genetic variation among populations was measured by means of the coefficient of gene differentiation $\left(G_{\mathrm{ST}}\right)$ as defined by Nei $(1973,1986)$.

Haplotypic frequencies for locus pairs were estimated from genotypic data using the expectation-maximization (EM) algorithm (Dempster et al, 1977; Excoffier and Slatkin, 1995). Computation of linkage or gametic disequilibrium from haplotypic frequency estimates was accomplished taking into account that many of the protein loci analysed are multiallelic (Weir and Cockerham, 1978; Weir, 1996). In this way, a separate disequilibrium coefficient $\left(D_{i j}\right)$ is defined for each pair of alleles, $A_{i}$ and $B_{j}$ at loci $A$ and $B$, respectively, as $D_{i j}=X_{i j}-p_{i} q_{j}$, where $X_{i j}$ is the frequency of gamete $A_{i} B_{j}$ and $p_{i}$ and $q_{j}$ are the corresponding allele frequencies. A normalized measure of the extent of gametic disequilibrium for each pair of alleles is computed as $D_{i j}^{\prime}=D_{i j} / D_{\max }$ (Lewontin, 1964), where $D_{\max }=\min \left[p_{i} q_{j},\left(1-p_{i}\right)\left(1-q_{j}\right)\right]$ when $D_{i j}<0$ or $D_{\max }=\min \left[p_{i}\left(1-q_{j}\right),\left(1-p_{i}\right) q_{j}\right]$, when $D_{i j}>0$. The extent of overall disequilibrium between all the alleles at two loci is measured by $D^{\prime}=\sum_{i=1}^{k} \sum_{j=1}^{l} p_{i} q_{j}\left|D_{i j}^{\prime}\right|$ where $k$ and $l$ are the number of alleles in loci $A$ and $B$, respectively (Hedrick, 1987; Zapata et al, 2001). The statistical significance of gametic disequilibrium for a particular allelic pair is performed by the $\chi^{2}$ statistic $\chi_{i j}^{2}=2 N D_{i j}^{2} / p_{i}\left(1-p_{i}\right) q_{j}\left(1-q_{j}\right)$ with one degree of freedom, where $N$ is the number of sampled individuals (Weir and Cockerham, 1978; Weir, 1996). The overall hypothesis that none of the $D_{i j}$ is different from zero was tested by means of $\chi^{2}$ tests $\left(\chi_{i j}^{2}\right)$ for each one of the allelic pairs with Bonferroni correction for multiple tests (Zapata et al, 2001). Also, a likelihood ratio test was computed as an overall test for gametic disequilibrium between loci (Slatkin and Excoffier, 1995).

Analysis of departures from Hardy-Weinberg proportions (exact test and $F_{\text {IS }}$ statistics) was performed using GENET-2 and GENEPOP v. 3.1 programs (Quesada et al, 1992; Raymond and Rousset, 1995). Estimation of haplotypic frequencies from genotypic data by means of the EM algorithm and computation of the likelihood ratio test were performed by the ARLEQUIN program (Schneider et al, 2000). The EM algorithm was always started from 100 random initial haplotype frequencies, to avoid nonconvergence problems in the iterative process and to ensure finding the global maximum likelihood estimate (Excoffier and Slatkin, 1995). The significance of the likelihood ratio test was based on the empirical distribution of likelihood ratios under the null hypothesis of gametic equilibrium generated from 20000 randomizations, that is, random permutations of alleles at each locus (Slatkin and Excoffier, 1996).

\section{Results}

The protein pattern revealed by two-dimensional gel electrophoresis of an individual foot sample of $M$. galloprovincialis is shown in Figure 2. In any given gel, approximately 1200 polypeptide spots could be routinely visualized by general protein staining. Our analysis was limited to a subset of 86 polypeptides selected on the basis of three criteria: (i) reproducibility, (ii) intensity and (iii) relative isolation on the gel (Rosenblum et al, 1983, 1984; Asakawa et al, 1985; Hanash et al, 1986a, b). The choice of spots was made by two investigators who had not previously scored any of them with respect to variability, that is, selected in an unbiased fashion. With respect to reproducibility, spots at the margins of the gel were discarded because of variable migration. The criterion for intensity was that if genetic variation were to result in two spots instead of one (ie a heterozygote), both spots would have a staining intensity above the background. With respect to isolation, spots in crowded regions or spots associated with streaking were not included in the analysis. We arbitrarily assign numbers to the spots to be analysed, working from the upper left to the lower right of the gel. All gels were scored independently by two investigators.

Genetic polymorphisms were detected as position mobility shifts due to charge alteration. All the putative polymorphisms exhibited gene dosage dependence in heterozygotes, which is consistent with a genetic basis. As an example, various genetic polymorphisms are illustrated in Figure 3. Allelic variants were named from the basic side of the gel to the acid one. Of the 86 protein spots examined, 32 and 26 exhibited genetic polymorphisms in the Ribadeo and Vilagarcía samples, respectively. The positions on the gel of the polypeptides scored in this study and the identity of five of them, determined by mass spectrometry (López et al, 2001), are indicated in Figure 4.

Genotype frequencies and analysis of Hardy-Weinberg deviations for the polymorphic protein loci in the Ribadeo and Vilagarcía samples are shown in Tables 1 and 2, respectively. Only three of a total of 32 polymorphic loci showed statistically significant departures from Hardy-Weinberg expectations in the Ribadeo sample. Locus 2 showed a significant heterozygote deficiency $\left(f_{\mathrm{T}}=+0.490, \quad P<0.01 ; \quad X^{2}=6.47, \quad P<0.01\right.$; exact test, $P=0.10$ ), while a significant heterozygote excess $\left(f_{\mathrm{T}}=-0.430, P<0.05 ; X^{2}=5.81, P<0.05\right.$; exact test, $P=0.03$ ) was found for locus 48 . For locus 46 , statistically significant deviations were not detected by the $f_{\mathrm{T}}$ and the $\chi^{2}$ tests $\left(f_{\mathrm{T}}=+0.171, P>0.05 ; X^{2}=5.74\right.$, $P>0.05)$ but the probability of the exact test was 0.0497 and a statistically significant heterozygote deficiency was detected for allele 20 at this locus $\left(f_{i i}=+0.424, P<0.05\right)$. In the Vilagarcía sample, only two loci (6 and 76) present statistically significant deviations from Hardy-Weinberg proportions $\left(f_{\mathrm{T}}=+0.703, P<0.05\right.$, for both loci). When a Bonferroni correction is applied in each sample to control for potential Type I errors due to the use of multiple tests, statistical significance of Hardy-Weinberg deviations is not found for any of these five loci. The deviations from Hardy-Weinberg expectations expressed by means of the two $F_{\text {IS }}$ statistics, $f_{\mathrm{C}}$ and $f_{\mathrm{T}}$, displayed similar values in both samples. In the Ribadeo sample, $f_{C}$ ranged from 0.426 to 0.478 and $f_{\mathrm{T}}$ varied between -0.430 and 0.490 


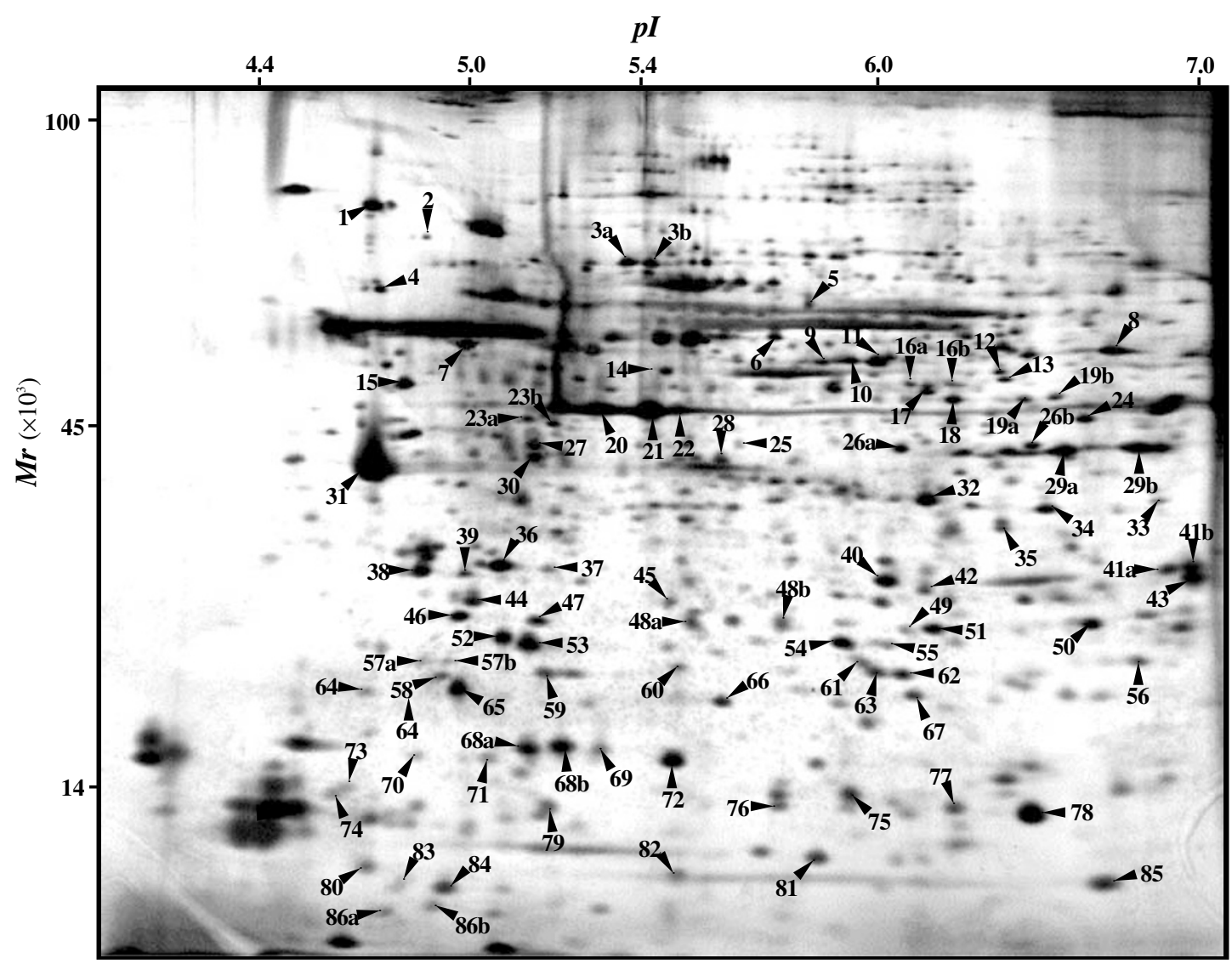

Figure 2 Two-dimensional protein pattern obtained from the foot of $M$. galloprovincialis. Numbers identify the 86 polypeptides analysed and letters $(\mathrm{a}=$ acidic, $\mathrm{b}=$ basic spot) indicate polypeptides for which variants were observed. The $\mathrm{pI}$ is indicated on the horizontal axis and the molecular weight on the vertical axis.
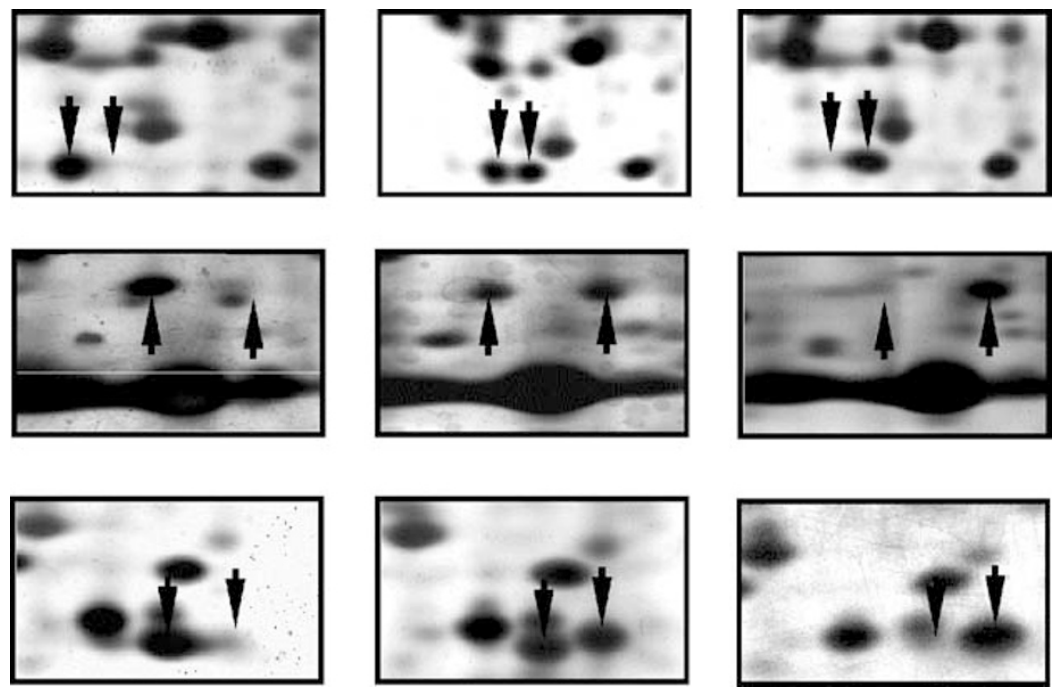

Figure 3 Examples of three genetic polymorphisms. From left to right, the acidic homozygote, the heterozygote and the basic homozygote are displayed. Arrows point to the location of absent and present allelic variants.

across loci. The mean values over loci were $-0.004 \pm 0.018$ and $-0.011 \pm 0.016$ for $f_{\mathrm{C}}$ and $f_{\mathrm{T}}$ respectively. In the Vilagarcía sample, $f_{C}$ ranged from -0.581 to 0.632 and $f_{\mathrm{T}}$ varied between -0.571 and 0.703 , the average values being $-0.065 \pm 0.032$ and $-0.033 \pm 0.032$, respectively. In both samples, the averages of $f_{\mathrm{T}}$ and $f_{\mathrm{C}}$ estimated from 2-DE polymorphisms are very close to the heterozygote excess expected by sampling from a population in Hardy-Weinberg equilibrium, which is $F_{\mathrm{IS}}=-(1 /(2 N-1))$ (Kirby, 1975; Robertson and Hill, 1984). Thus, the $F_{\text {IS }}$ value expected by sampling is -0.017 for Ribadeo $(N=30)$ and -0.066 for Vilagarcía 


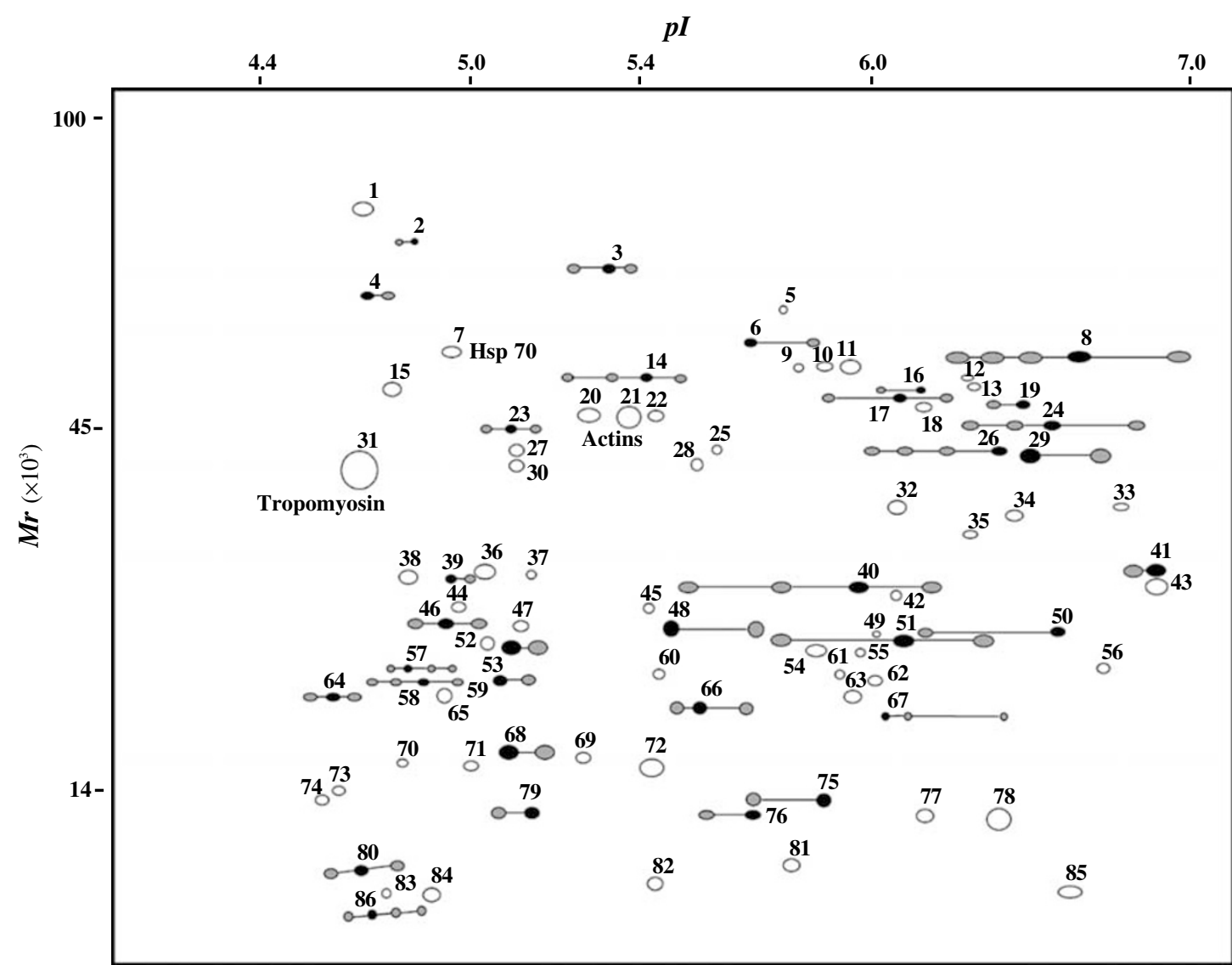

Figure 4 Schematic representation of the 86 polypeptides analysed. Polymorphic variants are joined with a line. The most frequent allelic variants are in black and the rarer are in grey. Monomorphic proteins are outlined.

$(N=8)$. It appears, therefore, that genotype data are generally consistent with their Hardy-Weinberg proportions for the Ribadeo and Vilagarcía populations, although significant deviations could be occurring in some specific loci, particularly towards a deficiency of heterozygote genotypes. Heterozygote deficiency is a common observation from several species of marine molluscs and has been described in $M$. galloprovincialis for some allozyme loci (Sanjuan et al, 1990, 1994; Raymond et al, 1997). Although no satisfactory explanation for this observation has yet been identified, the possibility that locus-specific factors such as selection or Wahlund effect are involved has been suggested (Raymond et al, 1997).

Indexes of genetic variability (expected heterozygosity, degree of polymorphism and number of alleles per locus) for the Ribadeo and Vilagarcía population samples are given in Table 3. Patterns of polymorphism characterized by the number and the frequency of the protein variants were similar in the two population samples. The Ribadeo sample showed 54 monomorphic and 32 polymorphic loci (16 loci with two, 12 loci with three and four loci with 4 alleles) while the Vilagarcía sample presented 60 monomorphic and 26 polymorphic loci (17 loci with two, 5 loci with three and 4 loci with four alleles). The estimates of genetic variation were also very similar for both populations. Average heterozygosity was $0.101 \pm 0.018$ and $0.114 \pm 0.021$ in Ribadeo and Vilagarcía, respectively. The degree of gene differentiation $\left(G_{\mathrm{ST}}\right)$ between the two populations for single loci ranged from
0 (locus16) to 0.544 (locus 23) and the $G_{\mathrm{ST}}$ estimated for the whole loci set was 0.067 . These estimates are higher than those reported for natural mussel populations of the Atlantic coast of the Iberian Peninsula based on allozyme data (Quesada et al, 1995). This could be due to the small sample size of the Vilagarcía sample as well as to the sampling process associated with mussel culture in rafts from individuals collected in natural populations.

A total of 406 two-locus associations were evaluated from 29 polymorphic loci of the Ribadeo population sample. Loci 2, 46 and 48 were not included in this analysis since Hardy-Weinberg departures were found at these three loci, and the maximum likelihood estimation of haplotype frequencies is based on the assumption of Hardy-Weinberg proportions (Hill, 1974; Excoffier and Slatkin, 1995). Statistical significance for gametic association between loci was detected in 18 pairs (4.43\%) by the likelihood ratio test and in 81 pairs $(19.95 \%)$ by $\chi^{2}$ tests (with Bonferroni correction) for each pair of alleles. When using a single $\chi^{2}$ test for the most frequent alleles at a given locus pair, significant associations were detected in 53 locus pairs (13.05\%). Overall, 92 (22.66\%) of 406 pairs of loci show statistically significant associations as detected by some of the different tests. Our results show that the $\chi^{2}$ tests detect more significant gametic associations than the likelihood ratio test. However, it must be emphasized that the statistical power for detecting significant gametic disequilibrium by the $\chi^{2}$ test is not large, particularly when allelic 


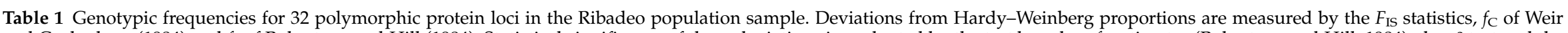

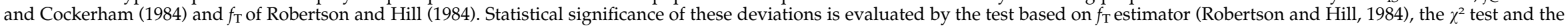
exact probability test

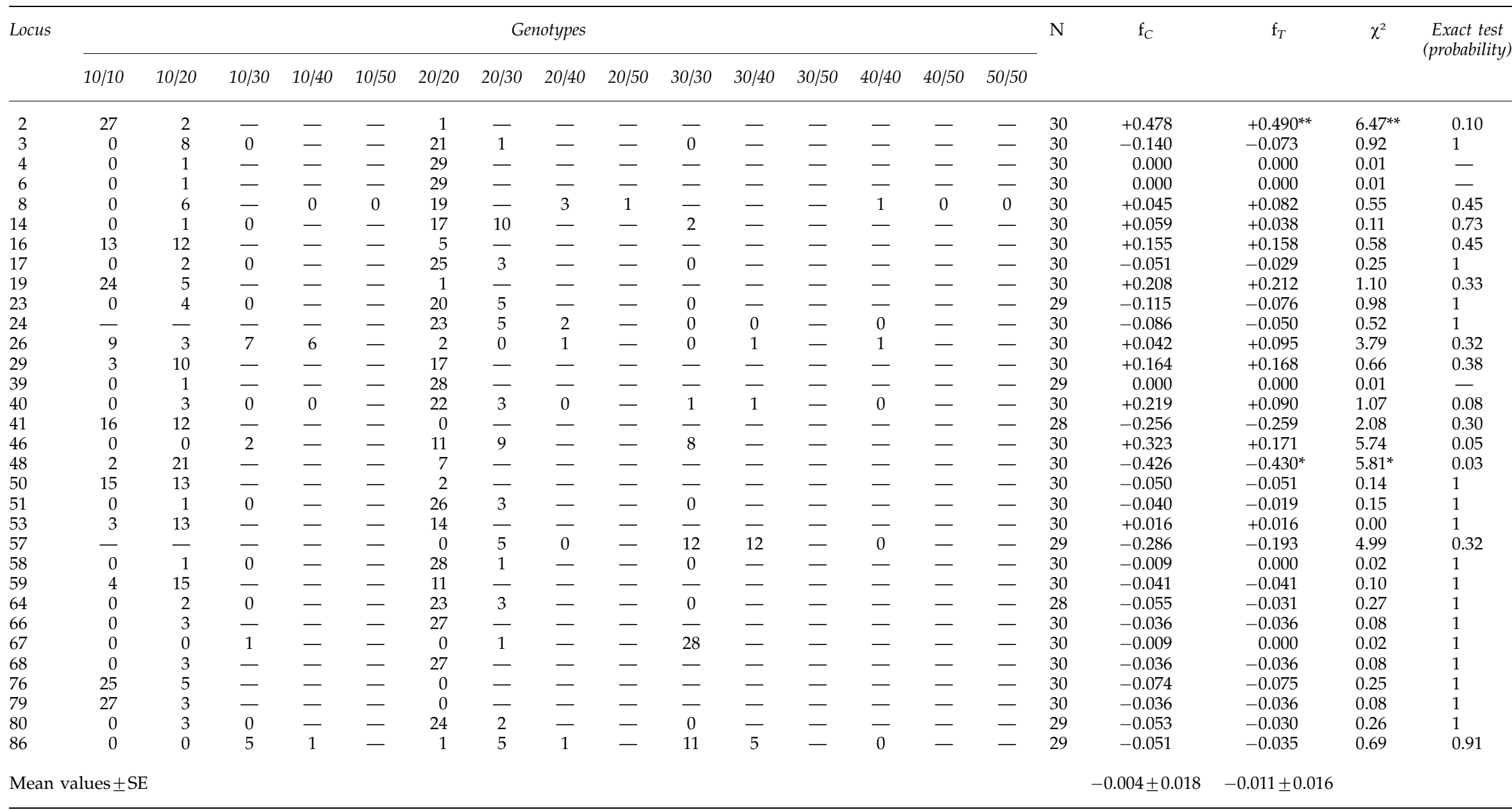

${ }^{*} P<0.05 .{ }^{* *} P<0.01$. 


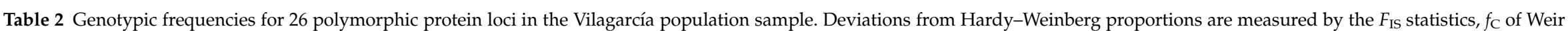

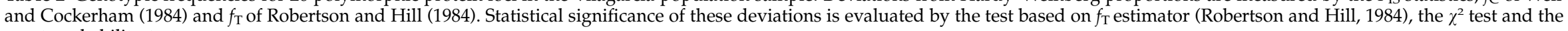
exact probability test

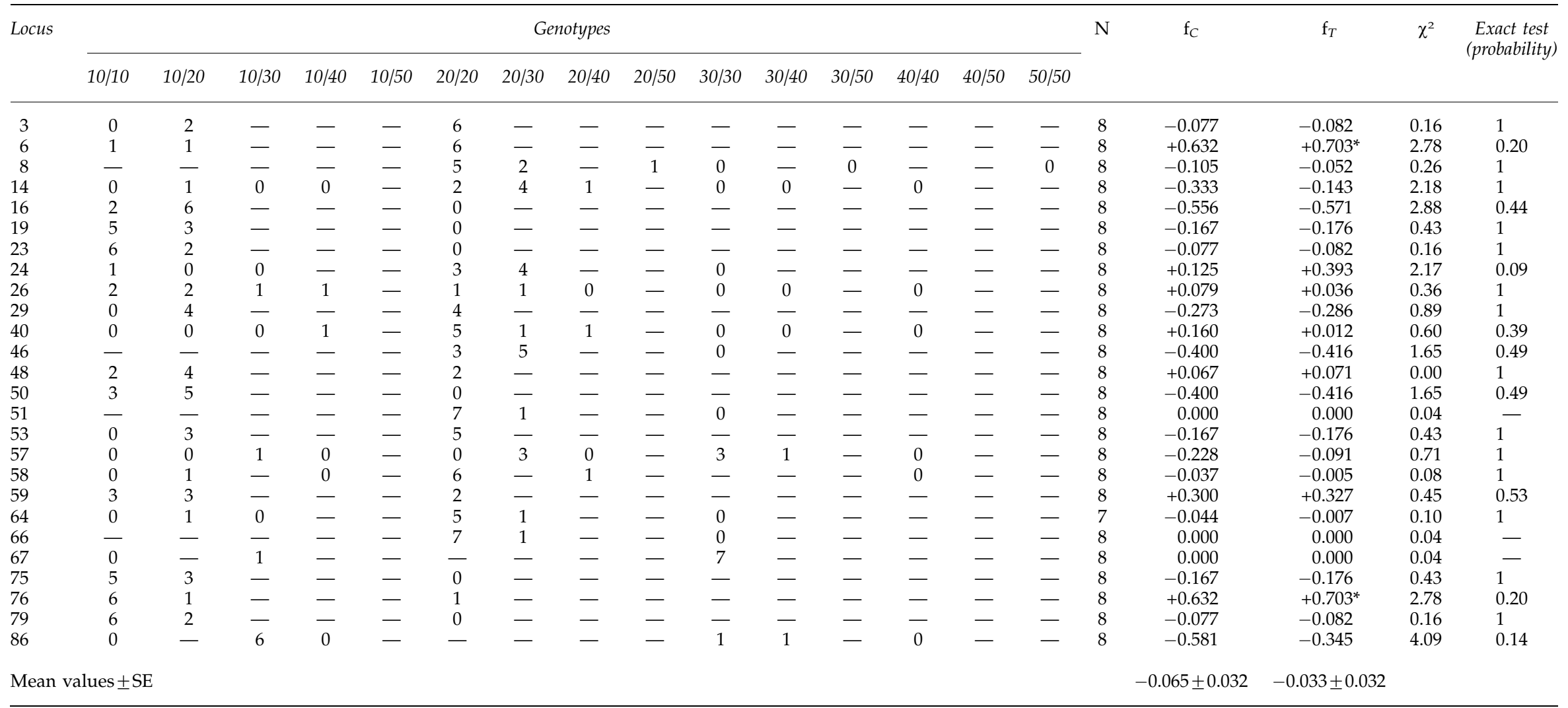

${ }^{*} P<0.05$. 
Table 3 Estimates of genetic variability from 2-DE in two populations of Mytilus galloprovincialis

\begin{tabular}{lcc}
\hline & Ribadeo & Vilagarcía \\
\hline Sample size & 30 & 8 \\
Proportion of polymorphic loci & 0.372 & 0.302 \\
Average number of alleles per locus & $1.61 \pm 0.10$ & $1.45 \pm 0.09$ \\
Average heterozygosity & $0.101 \pm 0.018$ & $0.114 \pm 0.021$ \\
\hline
\end{tabular}

frequencies are extreme and disequilibrium is not relatively intense (Brown, 1975; Zapata and Alvarez, 1992). This must be particularly considered in our case, given that the sample size is not large $(2 N=60)$. In general, two broad patterns of gametic disequilibrium can be observed in those pairs of loci where statistically significant associations are detected by tests. In 53 locus pairs, the statistical association is mainly due to the most frequent alleles, while in 39 locus pairs gametic disequilibrium is associated only with rare alleles (alleles at a low or intermediate frequency). In the first type of locus pair, the magnitude of gametic disequilibrium detected is high for the overall disequilibrium $\left(D^{\prime}=0.687 \pm 0.036\right)$ and for the disequilibrium of the most frequent alleles $\left(\left|D_{i j}^{\prime}\right|=0.699 \pm 0.037\right)$, while in those locus pairs where statistically significant disequilibrium is due to rare alleles, the extent of disequilibrium observed is clearly lower for both the overall disequilibrium $\left(D^{\prime}=0.411 \pm 0.040\right)$ and the disequilibrium exhibited by the most frequent alleles $\left(\left|D^{\prime}{ }_{i j}\right|=0.334 \pm 0.045\right)$.

From the disequilibrium analysis, groups of loci are detected in which all pairwise combinations exhibit statistically significant gametic disequilibrium. One of these clusters involving six loci $(8,17,24,39,79$ and 80$)$ is shown in Table 4. Overall $D^{\prime}$ for locus pairs in this cluster ranges from 0.224 to 1 with a mean value of $0.561 \pm 0.088$. In addition, three loci of this cluster $(39,79$ and 80$)$ show significant associations between the most frequent alleles for all pairwise combinations $\left(D^{\prime}{ }_{i j}\right.$ for the most frequent alleles ranging from 0.621 to 1 ). Also, a cluster involving
Table 5 Cluster of four loci $(58,76,79$ and 80$)$ showing statistically significant associations between all pairs. For each locus pair, the overall $D^{\prime}$ and the number of statistically significant $\chi_{i j}{ }^{2} /$ number of total $\chi^{2}$ (in parentheses) are indicated in the upper line; the $\left|D^{\prime}{ }_{i j}\right|$ and the $\chi_{i j}{ }^{2}$ values for the most frequent alleles (in parentheses) are shown in the lower line

\begin{tabular}{ccccc}
\hline & 58 & 76 & 79 & 80 \\
\hline 58 & - & & & \\
76 & $0.457(1 / 3)$ & - & - & \\
& $0.438\left(4.34^{*}\right)$ & & & \\
79 & $0.477(2 / 3)$ & $0.607(1 / 1)$ & & \\
& $0.458\left(8.15^{* *}\right)$ & $0.607\left(12.87^{* * *}\right)$ & & \\
80 & $0.492(3 / 9)$ & $0.365(2 / 3)$ & $0.636(2 / 3)$ & - \\
& $0.453\left(4.45^{*}\right)$ & $0.326\left(6.15^{*}\right)$ & $0.621\left(13.05^{* * *}\right)$ & \\
\hline
\end{tabular}

${ }^{*} P<0.05 .{ }^{* *} P<0.01,{ }^{* * *} P<0.001$.

four loci $(58,76,79$ and 80$)$ has been detected (Table 5). Overall $D^{\prime}$ for locus pairs in this cluster varies from 0.365 to 0.636 with an average value of $0.506 \pm 0.041$. In this cluster, all pairwise combinations show significant associations between the most frequent alleles $\left(D^{\prime}{ }_{i j}\right.$ range from 0.326 to 0.621 ). Other clusters involving three or four loci have also been detected.

\section{Discussion}

2-DE has been used to measure the degree of genetic variability for loci coding abundant proteins in the marine mussel M. galloprovincialis. Among the 86 polypeptides selected in an unbiased fashion for scoring for genetic variability, the natural population sample from Ribadeo exhibited such variation in $32(37.2 \%)$ polypeptides with an average heterozygosity of $0.101 \pm 0.018$. Similar results were obtained in a cultured population from Vilagarcía $(P=30.2 \%, H=0.114 \pm 0.021)$. These estimates of heterozygosity are clearly higher than those

Table 4 Cluster of six loci $(8,17,24,39,79$ and 80$)$ showing statistically significant associations between all pairs. For each locus pair, the overall $D^{\prime}$ and the number of statistically significant $\chi_{i j}{ }^{2}$ over the number of total $\chi^{2}$ (in parentheses) are indicated in the upper line; the $\left|D^{\prime}{ }_{i j}\right|$ and the $\chi_{i j}{ }^{2}$ values for the most frequent alleles (in parentheses) are shown in the lower line

\begin{tabular}{|c|c|c|c|c|c|c|}
\hline & 8 & 17 & 24 & 39 & 79 & 80 \\
\hline 8 & - & & & & & \\
\hline 17 & $\begin{array}{l}0.287(2 / 12) \\
0.202(0.89)\end{array}$ & - & & & & \\
\hline 24 & $\begin{array}{l}0.273(1 / 12) \\
0.188(1.12)\end{array}$ & $\begin{array}{l}0.224(1 / 9) \\
0.086(0.30)\end{array}$ & - & & & \\
\hline 39 & $\begin{array}{l}1(1 / 4) \\
1(3.84)\end{array}$ & $\begin{array}{l}1(2 / 3) \\
1\left(13.53^{* * *}\right)\end{array}$ & $\begin{array}{l}1(2 / 3) \\
1\left(7.29^{* *}\right)\end{array}$ & - & & \\
\hline 79 & $\begin{array}{l}0.598(1 / 4) \\
0.575\left(4.18^{*}\right)\end{array}$ & $\begin{array}{l}0.302(1 / 3) \\
0.258(2.33)\end{array}$ & $\begin{array}{l}0.301(1 / 3) \\
0.230(1.26)\end{array}$ & $\begin{array}{l}1(1 / 1) \\
1\left(18.29^{* * *}\right)\end{array}$ & - & \\
\hline 80 & $\begin{array}{l}0.282(2 / 12) \\
0.208(0.91)\end{array}$ & $\begin{array}{l}0.233(1 / 9) \\
0.160(1.16)\end{array}$ & $\begin{array}{l}0.282(1 / 9) \\
0.286(3.24)\end{array}$ & $\begin{array}{l}1(2 / 3) \\
1\left(10.66^{* *}\right)\end{array}$ & $\begin{array}{l}0.636(2 / 3) \\
0.621\left(13.05^{* * *}\right)\end{array}$ & - \\
\hline
\end{tabular}

${ }^{*} P<0.05 .{ }^{* *} P<0.01$. ${ }^{* * *} P<0.001$. 
Table 6 Estimates of genetic variability from two-dimensional and single-dimensional electrophoresis in animal species

\begin{tabular}{|c|c|c|c|c|c|c|c|}
\hline \multirow[t]{2}{*}{ Species/tissues } & \multicolumn{4}{|c|}{$2-D E$} & \multicolumn{3}{|c|}{$1-D E$} \\
\hline & $\begin{array}{l}\text { Sample } \\
\text { size }\end{array}$ & $\begin{array}{l}\text { No. of } \\
\text { loci }\end{array}$ & $\begin{array}{c}\text { Average } \\
\text { heterozygosity }\end{array}$ & Ref. & $\begin{array}{l}\text { No. of } \\
\text { loci }\end{array}$ & $\begin{array}{c}\text { Average } \\
\text { heterozygosity }\end{array}$ & Ref. \\
\hline \multicolumn{5}{|l|}{ Man (Homo sapiens) } & 71 & 0.067 & (18) \\
\hline Fibroblasts & 5 & 200 & 0.006 & (1) & 121 & 0.143 & (19) \\
\hline \multirow[t]{3}{*}{ Lymphocytes } & 28 & 186 & 0.024 & (2) & & & \\
\hline & 3 & 250 & $0.005 \pm 0.003$ & (3) & & & \\
\hline & 40 & 106 & $0.031 \pm 0.002$ & (4) & & & \\
\hline \multirow{2}{*}{ Erythrocytes } & 27 & 46 & $0.031 \pm 0.005$ & (5) & & & \\
\hline & 100 & 55 & $0.040 \pm 0.003$ & (6) & & & \\
\hline Platelets & 44 & 33 & 0.026 & (7) & & & \\
\hline \multirow{4}{*}{ Plasma } & 62 & 20 & $0.062 \pm 0.007$ & (8) & & & \\
\hline & 107 (a) & 23 & $0.045 \pm 0.006$ & (9) & & & \\
\hline & 110 (b) & 23 & $0.057 \pm 0.007$ & (9) & & & \\
\hline & 62 (c) & 23 & $0.080 \pm 0.011$ & & & & \\
\hline Brain & 145 & 176 & 0.0004 & (10) & & & \\
\hline \multirow[t]{2}{*}{ Kidney } & 25 & 83 & 0.000 & (11) & & & \\
\hline & & & & & 47 & 0.000 & $(12)$ \\
\hline \multicolumn{8}{|l|}{ Cheetah (Acinonyx jubatus) } \\
\hline Fibroblasts & 6 & 155 & 0.013 & (12) & & & \\
\hline \multirow{2}{*}{$\begin{array}{l}\text { Mouse (Mus musculus) } \\
\text { Kidney }\end{array}$} & & & & & 41 & 0.085 & (20) \\
\hline & - & 72 & 0.020 & (13) & & & \\
\hline \multicolumn{2}{|l|}{ Drosophila (D. melanogaster) } & & & & 19 & 0.132 & (20) \\
\hline Whole-body & 20 (e) & 54 & 0.040 & (14) & & & \\
\hline MRT(d) & $20(\mathrm{e})$ & 307 & 0.018 & (15) & & & \\
\hline \multicolumn{2}{|l|}{ Drosophila (D. simulans) } & & & & 79 & 0.118 & (21) \\
\hline Whole-body & $19(\mathrm{e})$ & 70 & 0.000 & (16) & & & \\
\hline $\operatorname{MRT}(d)$ & $20(\mathrm{e})$ & 295 & 0.028 & (15) & & & \\
\hline \multirow{3}{*}{$\begin{array}{l}\text { Mussel (Mytilus galloprovincialis) } \\
\text { Foot }\end{array}$} & & & & & 23 & 0.240 & $(22)$ \\
\hline & 30 & 86 & $0.101 \pm 0.018$ & (17) & & & \\
\hline & 8 & 86 & $0.114 \pm 0.021$ & & & & \\
\hline
\end{tabular}

Note: (1) Walton et al (1979); (2) Goldman and Merril (1983); (3) Hamaguchi et al (1981); (4) Hanash et al (1986a); (5) Rosenblum et al (1984); (6) Takahashi et al (1986); (7) Hanash et al (1986b); (8) Rosenblum et al (1983); (9) Asakawa et al (1985); (10) Comings (1982); (11) Smith et al (1980); (12) O'Brien et al (1983); (13) Racine and Langley (1980); (14) Leigh Brown and Langley (1979); (15) Coulthart and Singh (1988); (16) Ohnishi et al (1982); (17) This work; (18) Harris and Hopkinson (1972); (19) Nei and Graur (1984); (20) Nevo (1978); (21) Singh et al (1987); (22) Grant and Cherry (1985). (a) Amerindians; (b) Japanese; (c) Caucasoids; (d) MRT: Male reproductive tract; (e) isofemale lines.

previously reported by 2-DE for animal populations (see Table 6) and put $M$. galloprovincialis as the animal species with the highest genetic variability detected by 2-DE to date. M. galloprovincialis heterozygosity is nearly six-fold higher than the heterozygosity values of Drosophila (average of heterozygosity estimates from different studies weighted by the number of loci scored is 0.021 and 0.023 for $D$. melanogaster and D. simulans, respectively), mouse (0.020), cheetah (0.013) and man (weighted average from different tissues is 0.017). Our findings clearly show a need to extend the 2-DE analysis to an increased number of species in order to obtain a wider view on genetic variability for loci responsible for abundant proteins in natural populations.

When comparing 2-DE and 1-DE estimates of heterozygosity for different animal species, two aspects deserve consideration (see Table 6). Firstly, although the 2-DE data set is still not large, the range of variation of heterozygosity estimates for different animal species seems to be clearly smaller than that reported from allozymic data. In mammals, for example, the allozyme heterozygosity varies from 0 up to $22 \%$ in 321 species reviewed by Makarieva (2001). It has been shown that these variations can be mainly explained by differences in the number of loci studied (Makarieva, 2001). From this perspective, the larger number of loci analysed by 2 $\mathrm{DE}$ with respect to 1-DE could be one of the reasons explaining the small variation in 2-DE estimates of heterozygosity among animal species. Second, although $2-\mathrm{DE}$ variation is generally reduced, it parallels the allozymic data in that more variable species, as indicated by 1-DE, are also shown to be more variable from 2-DE analysis (see Table 6). In fact, there is a statistically significant correlation $(r=0.838$, d.f. $4, P<0.05)$ between heterozygosity estimates yielded by both techniques among the species included in Table 6 . Two alternative explanations for this discrepancy, not mutually exclusive, have been widely discussed in the literature (Edwards and Hopkinson, 1980; Aquadro and Avise, 1981; Wanner et al, 1982; Mc Lellan et al, 1983; De Vienne et al, 1996). For one, the group of proteins analysed on 2-D gels is intrinsically less variable than the soluble enzymes and proteins previously studied. For another, the technique of 2-DE is not capable of resolving many variants that are detectable by the conventional electrophoretic methods, since proteins are denatured and some differences of 
conformational nature could remain undetectable. In this respect, Wanner et al (1982) tested the ability of 2-DE to resolve the allelic variants of five loci previously studied by 1 -DE. 2-DE could resolve more than $90 \%$ of the variants originally detected by $1-\mathrm{DE}$ (16 of the 17). The unique allelic variant that remained undetectable for 2DE was attributed to a conformational variation. Furthermore, DNA sequence analysis for different electrophoretic classes at several enzyme loci ( $A d h, G p d h$, Sod, Est-5, Est-6 and Xdh) in Drosophila has revealed that most differences (75-100\%) in protein mobility detected by single electrophoresis are due to variations in the net charge of the protein (Riley et al, 1992; Veuille and King, 1995; Barbadilla et al, 1996). Therefore, because the conformational variations in protein structure seems to play a minor role in the electrophoretic mobility, the remarkable reductions in the level of variability detected by $2-\mathrm{DE}$ with respect to $1-\mathrm{DE}$, ranging from $58(M$. galloprovincialis) to $85.2 \%$ (man) from data in Table 6, can hardly be attributed to conformational changes undetected by 2-DE. This suggests that the more feasible explanation for the lower levels of genetic variability detected by 2-DE is that the group of proteins analysed by this technique is intrinsically less variable than the enzymes assayed by 1-DE.

Among a total of 406 two-locus pairs analysed for detecting linkage disequilibrium in the Ribadeo population sample, 92 show statistically significant associations. This is a quite large proportion (22.7\%), taking into account that the size of the studied sample is not very large $(2 N=60)$ and the statistical power of tests for detecting gametic disequilibrium is low when allelic frequencies are extreme or the disequilibrium is not relatively intense (Brown, 1975; Zapata and Alvarez, 1992). Furthermore, information on physical linkage between some protein loci can be extracted from the disequilibrium analysis. Thus, clusters of loci showing statistically significant disequilibrium between all the locus pairs have been found (Tables 4 and 5). In some cases, the significant disequilibrium is associated with rare alleles. In these cases, a strong linkage disequilibrium detected between two genetic loci may be due to the recent occurrence of disequilibrium rather than a close physical linkage of the two loci, since rare alleles are most likely to have arisen recently in the population by the introduction of new mutations. Most interesting are those cases where the significant disequilibria are associated with the most frequent alleles which are old alleles. Although there are many evolutionary forces that can cause an association between the alleles at different loci, the decay of genetic disequilibrium along generations is expected to be smaller for increasing physical linkage and it provides the rationale for inferring physical linkage from linkage disequilibrium (Jorde, 1995; Kaplan et al, 1995; Weir, 1996; Wu and Zeng, 2001). On this basis, a cluster of four loci $(58,76,79$ and 80 , Table 5) and several clusters of three loci $(39,79$ and 80 , Table 4 and data not shown) where statistically significant disequilibria are occurring between all pairwise combinations for common alleles have been found. It is very likely that some physical linkage must be occurring between those protein loci included in clusters. This information will be very useful for planning future experiments of linkage analysis from single-pair matings. The previous knowledge of sets of protein loci where physical linkage is present can be very useful in selecting informative families for traditional linkage analysis (Weir, 1996). To date, the available information on linkage of genetic markers is very scarce in marine mussels (Beaumont, 1994), so that investigations on this issue will be of great interest.

\section{Acknowledgements}

This research was supported by grant PGIDT00MAR20001PR from the Xunta de Galicia (Spain) to GA.

\section{References}

Aquadro CF, Avise JC (1981). Genetic divergence between rodent species assessed by using two-dimensional electrophoresis. Proc Natl Acad Sci USA 78: 3784-3788.

Asakawa J, Takahashi N, Rosenblum BB, Neel JV (1985). Twodimensional gel studies of genetic variation in the plasma proteins of Amerindians and Japanese. Hum Genet 70: 222230.

Barbadilla A, King LM, Lewontin RC (1996). What does electrophoretic variation tell us about protein variation? Mol Biol Evol 13: 427-432.

Beaumont, AR (1994). Linkage studies in Mytilus edulis, the mussel. Heredity 72: 557-562.

Brown AHD (1975). Sample sizes required to detect linkage disequilibrium between two of three loci. Theor Popul Biol 8: 184-201.

Comings DE (1982). Two-dimensional gel electrophoresis of human brain proteins. III. Genetic and non-genetic variations in 145 brains. Clin Chem 28: 798-804.

Coulthart MB, Singh RS (1988). Low genic variation in malereproductive-tract proteins of Drosophila melanogaster and $D$. simulans. Mol Biol Evol 5: 167-181.

Dempster AP, Laird NM, Rubin DB (1977). Maximum likelihood from incomplete data via the EM algorithm. $J R$ Stat Soc B 39: 1-38.

De Vienne D, Burstin J, Gerber S, Leonardi A, Le Guilloux M, Murigneux A et al (1996). Two-dimensional electrophoresis of proteins as a source of monogenic and codominant markers for population genetics and mapping the expressed genome. Heredity 76: 166-177.

Edwards Y, Hopkinson DA (1980). Are abundant proteins less variable? Nature 284: 511-512.

Excoffier L, Slatkin M (1995). Maximum-likelihood estimation of molecular haplotype frequencies in a diploid population. Mol Biol Evol 12: 921-927.

Goldman D, Merril CR (1983). Human lymphocyte polymorphisms detected by quantitative two-dimensional electrophoresis. Am J Hum Genet 35: 827-837.

Grant WS, Cherry MI (1985). Mytilus galloprovincialis Lmk. in southern Africa. I Exp Mar Biol Ecol 90: 179-191.

Guo SW, Thompson EA (1992). Performing the exact test of Hardy-Weinberg proportion for multiple alleles. Biometrics 48: $361-372$.

Hamaguchi H, Ohta A, Mukai R, Yabe T, Yamada M (1981). Genetic analysis of human lymphocyte proteins by twodimensional electrophoresis. 1. Detection of genetic variant polypeptides in PHA-stimulated peripheral blood lymphocytes. Hum Genet 59: 215-220.

Hanash SM, Baier LJ, Welch D, Kuick R, Galteau M (1986a). Genetic variants detected among 106 lymphocyte polypeptides observed in two-dimensional gels. Am J Hum Genet 39: 317-328.

Hanash SM, Neel JV, Baier LJ, Rosenblum BB, Niezgoda W, Markel D (1986b). Genetic analysis of thirty-three platelet polypeptides detected in two-dimensional polyacrylamide gels. Am J Hum Genet 38: 352-360. 
Harris H, Hopkinson DA (1972). Average heterozygosity per locus in man: An estimate based on the incidence of enzyme polymorphisms. Ann Hum Genet 36: 9-20.

Hedrick PW (1987). Gametic disequilibrium measures proceed with caution. Genetics 117: 331-341.

Hill WG (1974). Estimation of linkage disequilibrium in randomly mating populations. Heredity 33: 229-239.

Jorde LB (1995). Linkage disequilibrium as a gene-mapping tool. Am J Hum Genet 56: 11-14.

Kaplan NL, Hill WG, Weir BS (1995). Likelihood methods for locating disease genes in nonequilibrium populations. Am J Hum Genet 56: 18-32.

Kirby GC (1975). Heterozygote frequencies in small subpopulations. Theor Popul Biol 8: 31-48.

Leigh Brown AJ, Langley CH (1979). Reevaluation of level of genic heterozygosity in natural populations of Drosophila melanogaster by two-dimensional electrophoresis. Proc Natl Acad Sci USA 76: 2381-2384.

Lewontin RC (1964). The interaction of selection and linkage. I. General considerations; heterotic models. Genetics 49: 49-67.

López JL, Mosquera E, Fuentes J, Marina A, Vázquez J, Alvarez G. (2001). Two-dimensional gel electrophoresis of Mytilus galloprovincialis: differences in protein expression between intertidal and cultured mussels. Mar Ecol Prog Ser 224: 149-156.

Louis EJ, Dempster ER (1987). An exact test for HardyWeinberg and multiple alleles. Biometrics 43: 805-811.

Makarieva AM. (2001). Variance of protein heterozygosity in different species of mammals with respect to the number of loci studied. Heredity 87: 41-51.

McLellan T, Ames GF, Nikaido K (1983). Genetic variation in proteins: Comparison of one-dimensional and two-dimentional gel Electrophoresis. Genetics 104: 381-390.

Morrissey JH (1981). Silver stain proteins in polyacrylamide gels: a modified procedure with enhanced uniform sensitivity. Anal Biochem 117: 307-310.

Neel JV (1990). Average locus differences in mutability related to protein 'class': a hypothesis. Proc Natl Acad Sci USA 87: 2062-2066.

Nei M (1973). Analysis of gene diversity in subdivided populations. Proc Natl Acad Sci USA 70: 3321-3323.

Nei M (1978). Estimation of average heterozygosity and genetic distance from a small number of individuals. Genetics 89 583-590.

Nei M (1986). Definition and estimation of fixation indices. Evolution 40: 643-645.

Nei M, Graur D (1984). Extent of protein polymorphism and the neutral mutation theory. Evol Biol 17: 73-118.

Nevo E (1978). Genetic variation in natural populations: patterns and theory. Theor Popul Biol 13: 121-177.

O'Brien SJ, Wildt DE, Goldman D, Merril CR, Bush M (1983) The cheetah is depauperate in genetic variation. Science $\mathbf{2 2 1}$ 459-462.

O'Farrell PH (1975). High resolution two-dimensional electrophoresis of proteins. J Biol Chem 250: 4007-4021.

Ohnishi S, Leigh Brown AJ, Voelker RA, Langley CH (1982). Estimation of genetic variability in natural populations of Drosophila simulans by two-dimensional and starch gel electrophoresis. Genetics 100: 127-136.

Quesada H, Sanjuan J, Sanjuan A (1992). GENET-2 a BASIC program for the analysis of deviations from Hardy-Weinberg law. I Hered 83: 460-461.

Quesada H, Zapata C, Alvarez G (1995). A multilocus allozyme discontinuity in the mussel Mytilus galloprovincialis: the interaction of ecological and life-history factors. Mar Ecol Prog Ser 116: 99-115.

Racine RR, Langley DH (1980). Genetic heterozygosity in a natural population of Mus musculus assessed using twodimensional electrophoresis. Nature 283: 855-857.

Raymond M, Rousset F (1995). GENEPOP (version 1.2) population genetics software for exact test and ecumenicism. J Hered 86: 248-249.
Raymond M, Vääntö RL, Thomas F, Rousset F, Meeüs T, Renaud F (1997). Heterozygote deficiency in the mussel Mytilus edulis species complex revisited. Mar Ecol Prog Ser 156: 225-237.

Riley MA, Kaplan SR, Veuille M (1992). Nucleotide polymorphism at the xanthine dehydrogenase locus in Drosophila pseudoobscura. Mol Biol Evol 9: 56-69.

Robertson A, Hill WG (1984). Deviations from Hardy-Weinberg proportions sampling variances and use in estimation of inbreeding coefficients. Genetics 107: 703-718.

Rosenblum BB, Neel JV, Hanash SM (1983). Two-dimensional electrophoresis of plasma polypeptides reveals 'high' heterozygosity indices. Proc Natl Acad Sci USA 80: 5002-5006.

Rosenblum BB, Neel JV, Hanash SM, Joseph JL, Yew N (1984). Identification of genetic variants in erythrocyte lysate by twodimensional gel electrophoresis. Am J Human Genet 36: 601612.

Rousset F, Raymond M (1995). Testing heterozygote excess and deficiency. Genetics 140: 1413-1419.

Sanjuan A, Quesada H, Zapata C, Alvarez G (1990). On the occurrence of Mytilus galloprovincialis Lmk. on the N.W. coast of the Iberian Peninsula. J Exp Mar Biol Ecol 143: 1-14.

Sanjuan A, Zapata C, Alvarez G (1994). Mytilus galloprovincialis and M. edulis on the coasts of the Iberian Peninsula. Mar Ecol Prog Ser 113: 131-146.

Schneider S, Roessli D, Excoffier L (2000). Arlequin: a software for population genetics data analysis. Ver. 2.000. Genetics and Biometry Laboratory, Department of Anthropology, University of Geneva.

Singh RS, Choudhary M, David JR (1987). Contrasting patterns of geographic variation in cosmopolitan sibling species Drosophila melanogaster and Drosophila simulans. Biochem Genet 25: $27-40$.

Slatkin M, Excoffier L (1996). Testing for linkage disequilibrium in genotypic data using the Expectation-Maximization algorithm. Heredity 76: 377-383.

Smith SC, Racine RR, Langley CH (1980). Lack of genic variation in the abundant proteins of human kidney. Genetics 96: 967-974.

Takahashi N, Neel JV, Nagahata-Shimoichi, Asakawa J, Tanaka Y, Satoh C. (1986). Inherited electrophoretic variants detected in a Japanese population with two-dimensional gels of erythrocyte lysates. Ann Hum Genet 50: 313-325.

Veuille M, King M (1995). Molecular basis of polymorphism at the esterase 5B locus in Drosophila pseudoobscura. Genetics 141: 255-262.

Walton KE, Styer D, Gruenstein EI (1979). Genetic polymorphism in normal human fibroblasts as analysed by twodimensional polyacrylamide gel electrophoresis. J Biol Chem 254: 7951-7960.

Wanner LA, Neel JV, Meisler MH (1982). Separation of allelic variants by two-dimensional electrophoresis. Am J Hum Genet 34: 209-215.

Ward RD, Skibinski DOF, Woodwark M (1992). Protein heterozygosity, protein structure, and taxonomic differentiation. Evol Biol 26: 73-159.

Weir BS (1996). Genetic Data Analysis II. Sinauer: Sunderland, MA.

Weir BS, Cockerham CC (1978). Testing hypotheses about linkage disequilibrium with multiple alleles. Genetics 88: 633642.

Weir BS, Cockerham CC (1984). Estimating $f$-statistics for the analysis of population structure. Evolution 38: 1358-1370.

$\mathrm{Wu} \mathrm{R}$, Zeng Z-B (2001). Joint linkage and linkage disequilibrium mapping in natural populations. Genetics 157: 899-909.

Zapata C, Alvarez G (1992). The detection of gametic disequilibrium between allozyme loci in natural populations of Drosophila. Evolution 46: 1900-1917.

Zapata C, Rodríguez S, Visedo G, Sacristán F (2001). Spectrum of nonrandom associations between microsatellite loci on human chromosome 11p15. Genetics 158: 1235-1251. 